\title{
Enhanced Thrombolysis Induced by Argatroban or Activated Protein $C$ in the Presence or Absence of Staphylokinase, Measured in an in vivo Animal Model Using Mesenteric Arterioles
}

\author{
Masaru Hashimoto ${ }^{a, b}$ Sadahiro Watanabe ${ }^{d}$ Kazuhiro Oiwa $^{e}$ \\ Yoshio Ohta ${ }^{f}$ Takeo Kishib,c Tadashi Okamotob,c \\ John C. Giddings 9 Junichiro Yamamoto ${ }^{a, b}$ \\ aLaboratory of Physiology, Faculty of Nutrition, ${ }^{b}$ High Technology Research Centre and \\ 'Department of Biological Chemistry, Faculty of Pharmaceutical Sciences, \\ Kobe Gakuin University, dDivision of Basic Medical Science, Kobe City College of Nursing, \\ e Communications Research Laboratory, Kansai Advanced Research Centre, Kobe, and \\ ${ }^{f}$ First Department of Pathology, Kinki University School of Medicine, Osaka, Japan; \\ gDepartment of Haematology, University of Wales College of Medicine, Cardiff, UK
}

\section{Key Words}

Endogenous thrombolysis . Thrombin

inhibitors . Activated protein C

\begin{abstract}
Successful administration of thrombolytic agents is associated with vessel reocclusion in a high proportion of cases. We have previously established an animal model to investigate platelet-rich thrombolytic mechanisms in vivo and demonstrated that recombinant staphylokinase (rSAK)-induced thrombolysis was enhanced by the concomitant administration of the direct thrombin inhibitor argatroban. The present study expanded the use of this model by comparing
\end{abstract}

\begin{tabular}{ll}
\hline KARGER & ( ) 2001 S. Karger AG, Basel \\
Fax + 4161306 1234-0147/01/0312-0080\$17.50/0 \\
$\begin{array}{l}\text { E-Mail karger@karger.ch } \\
\text { www.karger.com }\end{array}$ & $\begin{array}{l}\text { Accessible online at: } \\
\text { www.karger.com/journals/hae }\end{array}$
\end{tabular}

arterial and venous thrombolysis using advanced image analysis software. Mural thrombi were formed by Helium-Neon laser irradiation in mesenteric arterioles and were shown to be lysed, dose-dependently, by smaller amounts of rSAK than those required in venules. Activated protein C (APC), as well as argatroban, enhanced the rSAK-induced thrombolysis. APC or argatroban also induced thrombolysis in the absence of rSAK, and the effect was inhibited by tranexamic acid. The enhanced thrombolysis induced by APC or argatroban in the presence or absence of rSAK may be due to increased endogenous thrombolysis mediated by the inhibition of thrombin activity or delayed thrombin generation.

Copyright $\odot 2001$ S. Karger AG, Basel

\footnotetext{
J. Yamamoto, $\mathrm{PhD}$

Laboratory of Physiology, Faculty of Nutrition

Kobe Gakuin University, Nishi-ku

Kobe 651-2180 (Japan)

Fax +81 78974 5689, E-Mail yamamoto@nutr.kobegakuin.ac.jp
} 


\section{Introduction}

Plasminogen activator (PA) provides an effective means of treatment for patients with arterial thrombosis such as occurs in acute myocardial and cerebrovascular infarction. PA alone dissolves thrombi, but induces transient thrombin activity and is associated with reocclusion in a high proportion of cases [1, 2]. In recent multicentre trials of thrombolysis therapy, antithrombotic agents have therefore been administered together with PA [3, 4].

We have previously established a simple, accurate and reproducible animal model of thrombolysis in vivo in which platelet-rich thrombi were initially formed by HeliumNeon (He-Ne) laser irradiation of rat mesenteric venules. The controlled administration of therapeutic agents enabled a detailed study of thrombolytic mechanisms and provided novel information on the efficiency of potential therapeutic procedures $[5,6]$. We have also shown, however, that differences exist between arterioles and venules with regard to leucocyte behaviour and the effects of aspirin on thrombus formation [7]. In the present study, we have therefore expanded our model to quantitate thrombolytic mechanisms in arterioles in vivo using advanced image analysis software. The main aim of the study was to assess the simultaneous effects of the specific thrombin inhibitor argatroban and of activated protein C (APC) on PA-induced thrombolysis.

\section{Materials and Methods}

\section{Animals}

Male Wistar ST rats aged 8 weeks and weighing 230-270 g were obtained from SLC Co. Ltd. (Hamamatsu, Japan). The animals were allowed to drink ad libitum and were fasted overnight prior to the thrombolytic experiments to suppress the peristaltic movement of the intestines and to minimise the effect of diet. All procedures were conducted in compliance with the Guiding Principles for the Care and Use of Animals in the Field of Physiological Sciences, published by the Physiological Society of Japan.

\section{Agents}

Recombinant staphylokinase (rSAK, $1.0 \mathrm{mg} / \mathrm{ml}$ ) was donated by Yakult Co. Ltd. (Tokyo, Japan) and was stored at $-80^{\circ} \mathrm{C}$. It was dissolved and diluted in $0.05 \%$ Tween $80 /$ phosphate-buffered saline (PBS, pH 7.4) immediately before use. Argatroban (Novastan, $0.5 \mathrm{mg} / \mathrm{ml}$ ) was purchased from Tokyo Tanabe Pharmaceutical Co. Ltd. (Tokyo, Japan) and diluted in physiological saline. APC $3.5 \mathrm{mg} / \mathrm{ml}$ was donated by Chemo-Sero-Therapeutic Research Institute (Kumamoto, Japan) and was stored at $-80^{\circ} \mathrm{C}$. It was dissolved and diluted in $20 \mathrm{~m} M$ citrate $/ 0.7 \% \mathrm{NaCl} / 0.5 \%$ glycine (pH 7.0) immediately before use. Tranexamic acid (AMCA) was provided by Daiichi Pharmaceutical Co. Ltd. (Tokyo, Japan) and was dissolved and diluted in physiological saline.

\section{He-Ne Laser-Induced Thrombosis and}

\section{Thrombolysis}

Microvascular thrombi were produced in rat mesenteric arterioles by a slight modification of the method described previously $[8,9]$. Briefly, animals were anaesthetised with Nembutal $(70 \mathrm{mg} / \mathrm{kg}$, i.m.), and cannulae (PE50: inner diameter $0.58 \mathrm{~mm}$, outer diameter $0.97 \mathrm{~mm}$ ) were inserted into both femoral veins for the administration of test substances and Evans blue. The mesentery was secured flat in Tyrode solution at $37^{\circ} \mathrm{C}$ on the stage of a microscope. Arterioles (inner diameter 35-45 $\mu \mathrm{m}$ ) were irradiated with a He$\mathrm{Ne}$ laser beam at the midpoint between the internal vessel wall and the centre line of the lumen after the injection of Evans blue $(14.2 \mathrm{mg} / \mathrm{kg})$. The power and diameter of the laser spot at the focal plane were $15 \mathrm{~mW}$ and $15 \mu \mathrm{m}$, respectively, and irradiation was repeated for $2 \mathrm{~s}$ at 15 -second intervals until the extent of the thrombus reached $90 \%$ of the lumen diameter. The thrombus was then allowed to stabilise for $10 \mathrm{~min}$ before rSAK and/or test substances were given through the femoral vein [5]. $\operatorname{rSAK}(0.39-3.9 \mathrm{mg} / 7.7 \mathrm{ml} / \mathrm{kg} / \mathrm{h})$, argatroban $(0.67$ or $2.0 \mathrm{mg} / 4.0 \mathrm{ml} / \mathrm{kg} / \mathrm{h})$ and/or AMCA $(121 \mathrm{mg} / 7.7 \mathrm{ml} / \mathrm{kg} / \mathrm{h}$ ) were infused for $60 \mathrm{~min}$ through the femoral veins. APC $(0.54$ or $1.62 \mathrm{mg} / 2.31 \mathrm{ml} / \mathrm{kg})$ was given as a bolus injection. Experiments were performed in as short a time as possible to minimise possible inter-batch variations in the animal model. 


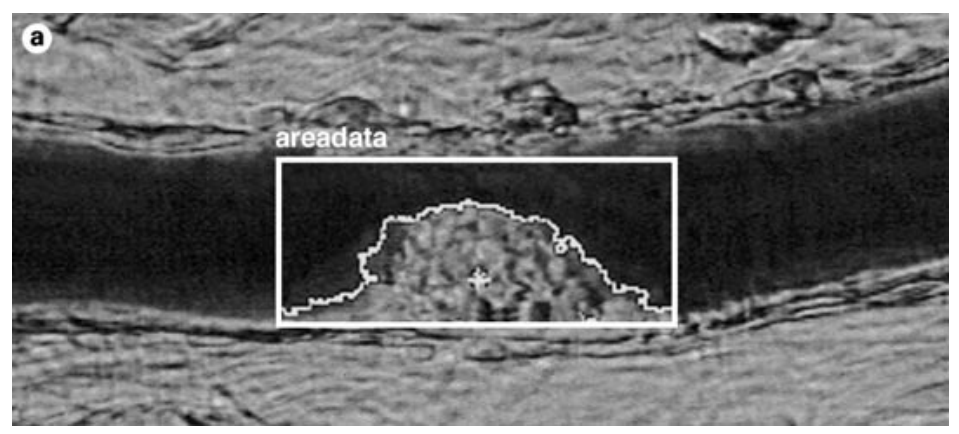

Fig. 1. Evaluation of thrombus size using Image Analyst software. a The thrombus within the lumen of the arteriole is boxed and a threshold level defining the thrombus area is set on a grey scale. The extent of thrombolysis was calculated from the following formula: $A_{n} \times G_{n} / A_{0} \times G_{0}$, where $A_{0}$ is the thrombus area immediately before infusion of the test agents (time 0 ) and $A_{n}$ is the area of the thrombus at time intervals during thrombolysis (time $\mathrm{n}$ ). $\mathrm{G}_{0}$ is the grey reading at time 0 and $G_{n}$ is the equivalent reading at time $n$. b Three-dimensional thrombus image obtained by multiplication of area and grey scale. $\mathrm{T}=$ Thrombus; $\mathrm{V}=$ vessel wall; $\mathrm{L}=$ lumen.

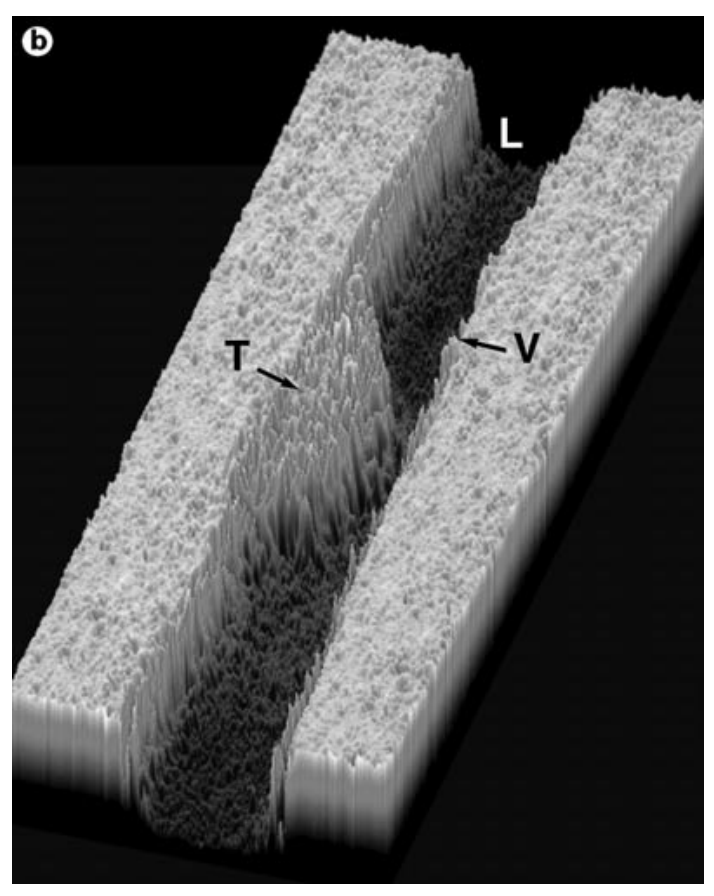

Computerised Image Analysis of Thrombolysis

The process of thrombolysis was continuously recorded on a videotape recorder. Subsequently, images at fixed time intervals were transferred to a personal computer and were analysed with Image Analyst software (Automatix, USA). The method used to calculate the dimensions of a thrombus is shown in figure 1 . The consolidated thrombus within the vessel lumen was enclosed by a box. The grey scale threshold level was set to delineate the thrombus and the thrombus area was measured. The thrombus size was calculated by multiplication of area and grey scale value. This calcu- lation provided an estimate of the thrombus volume. Thrombus size during thrombolysis was expressed relative to that of the thrombus immediately before agent administration.

\section{Transmission Electron Microscopy}

Sections of mesenteric arterioles with or without thrombi were fixed with $2.5 \%$ glutaraldehyde in $0.1 \mathrm{M}$ phosphate buffer, $\mathrm{pH} 7.4$ postfixed with $1 \%$ osmium tetroxide, dehydrated through a graded series of acetone and embedded in epoxy resin. Ultrathin sections were stained with uranil acetate and lead citrate, and 

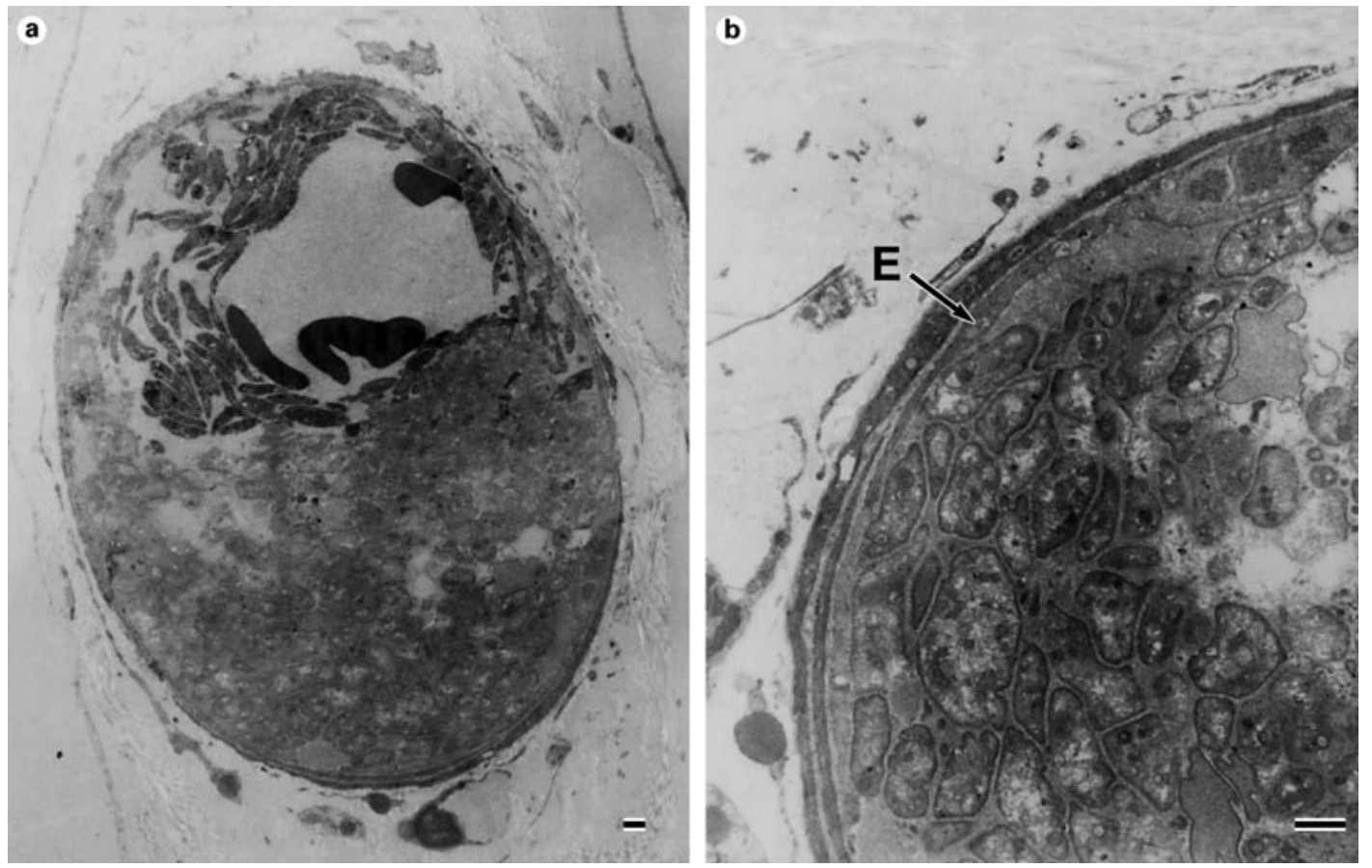

Fig. 2. Representative transmission electron micrographs of thrombi in arterioles. a Magnification $\times 3,400$, bar $=1.0 \mu \mathrm{m} . \mathbf{b} \times 17,600$, bar $=0.5 \mu \mathrm{m} . \mathrm{E}=$ Endothelial cell.

were examined under a JEM 2000EX electron microscope.

Statistical Analysis

The results were analysed by multiple repeated ANOVA followed by Duncan's post hoc test and were expressed as mean \pm SEM.

\section{Results}

\section{Transmission Electron Microscopy}

Observation of He-Ne Laser-Induced

\section{Thrombi}

Representative electron micrographs are shown in figure 2. The thrombi formed in arterioles were shown to be composed of densely packed platelets. Within the thrombi, the platelets were degranulated. Erythrocytes and fibrin were not observed. Moreover, fibrin fibres were not detected even at high magnification. Endothelial cells under the thrombi were morphologically intact and denudation was not evident.

\section{Thrombolysis Induced by rSAK}

rSAK was infused after stabilising the thrombi for $10 \mathrm{~min}$. The process of thrombolysis is shown in figure 3. Thrombus size decreased over time in the absence of rSAK. Thrombolysis was significantly enhanced by rSAK above a dose of $0.39 \mathrm{mg} / 7.7 \mathrm{ml} / \mathrm{kg} / \mathrm{h}$ in a dose-dependent manner. The minimum effective dose of rSAK was $0.77 \mathrm{mg} / 7.7 \mathrm{ml} / \mathrm{kg} / \mathrm{h}$ and was evident for at least $25 \mathrm{~min}$ after infusion. 
Fig. 3. Thrombolysis induced by various doses of rSAK in rat mesenteric arterioles. rSAK or PBS was infused at a rate of $7.7 \mathrm{ml} / \mathrm{kg} / \mathrm{h}(0-$ $60 \mathrm{~min}$ ). $\square=3.9 \mathrm{mg} / 7.7 \mathrm{ml} / \mathrm{kg} / \mathrm{h}$; $\triangle=1.9 \mathrm{mg} / 7.7 \mathrm{ml} / \mathrm{kg} / \mathrm{h} ; \diamond=0.77$ $\mathrm{mg} / 7.7 \mathrm{ml} / \mathrm{kg} / \mathrm{h} ; \nabla=0.39 \mathrm{mg} / 7.7$ $\mathrm{ml} / \mathrm{kg} / \mathrm{h} ; \mathrm{O}=$ PBS (control). $\mathrm{n}=$ $5-6$ rats in each group. ${ }^{*} \mathrm{p}<0.05$; $* * \mathrm{p}<0.01$ versus control at each time interval.

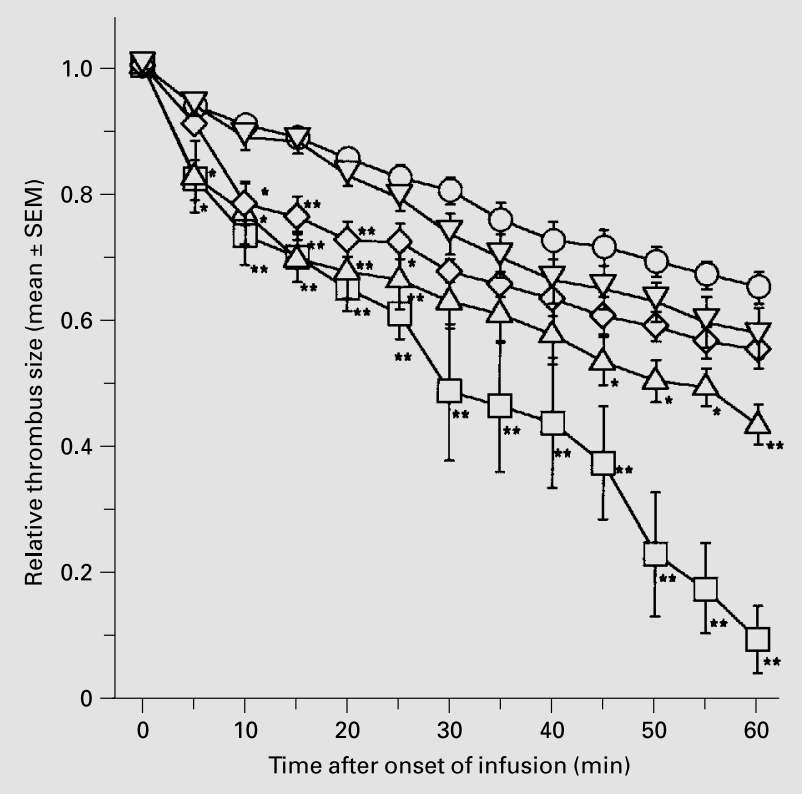

nificantly enhanced thrombolysis at a dose of $2.0 \mathrm{mg} / 4.0 \mathrm{ml} / \mathrm{kg} / \mathrm{h}$. At a dose of $0.67 \mathrm{mg} /$ $4.0 \mathrm{ml} / \mathrm{kg} / \mathrm{h}$, argatroban did not enhance rSAK-induced thrombolysis.

\section{Effect of Coagulation Inhibitors on}

Spontaneous Thrombolysis in the Absence of $r S A K$

Effect of AMCA and APC Alone on Spontaneous Thrombolysis. AMCA alone at a dose of $121 \mathrm{mg} / 7.7 \mathrm{ml} / \mathrm{kg} / \mathrm{h}$ and APC alone at a dose of $1.62 \mathrm{mg} / 2.31 \mathrm{ml} / \mathrm{kg}$ were given as bolus injections after stabilisation of the thrombus. The results are shown in figure 6. AMCA alone inhibited spontaneous thrombolysis compared to the control group (PBS + vehicle). APC at a dose of $1.62 \mathrm{mg} / 2.31 \mathrm{ml} / \mathrm{kg}$ significantly enhanced spontaneous thrombolysis. AMCA (121 mg/7.7 ml/kg/h) infused together with APC at a dose of $1.62 \mathrm{mg} /$ 
Fig. 4. Effect of APC administration on rSAK-induced thrombolysis in rat mesenteric arterioles. rSAK at a dose of $0.77 \mathrm{mg} / \mathrm{kg} / \mathrm{h}$ was infused through a femoral vein. APC at a dose of 0.54 or $1.62 \mathrm{mg} /$ $2.31 \mathrm{ml} / \mathrm{kg}$ or vehicle was administered as a bolus injection ( $0 \mathrm{~min})$ immediately before rSAK infusion (0-60 min). $\square=1.62 \mathrm{mg} / 2.31 \mathrm{ml} /$ $\mathrm{kg}+\mathrm{rSAK} ; \triangle=0.54 \mathrm{mg} / 2.31 \mathrm{ml} /$ $\mathrm{kg}+\mathrm{rSAK} ; \mathrm{O}=$ vehicle $+\mathrm{rSAK}$ (control). $\mathrm{n}=6-8$ rats in each group. $* \mathrm{p}<0.05 ; * * \mathrm{p}<0.01$ versus vehicle + rSAK at each time interval.

Fig. 5. The effect of concomitant argatroban administration on rSAK-induced thrombolysis in rat mesenteric arterioles. rSAK and argatroban were infused through separate femoral veins at a dose of $0.77 \mathrm{mg} / 7.7 \mathrm{ml} / \mathrm{kg} / \mathrm{h}$ and 0.6 or 2.0 $\mathrm{mg} / 4.0 \mathrm{ml} / \mathrm{kg} / \mathrm{h}$, respectively $(0-$ $60 \mathrm{~min}) . \square=$ Argatroban $(2.0 \mathrm{mg} /$ $4.0 \mathrm{ml} / \mathrm{kg} / \mathrm{h})+\mathrm{rSAK} ; \Delta$ = argatroban $(0.67 \mathrm{mg} / 4.0 \mathrm{ml} / \mathrm{kg} / \mathrm{h})+\mathrm{rSAK}$; $\mathrm{O}=$ vehicle + rSAK (control). $\mathrm{n}=$ $6-8$ rats in each group. ${ }^{*} \mathrm{p}<0.05$; $* * \mathrm{p}<0.01$ versus vehicle + rSAK at each time interval.
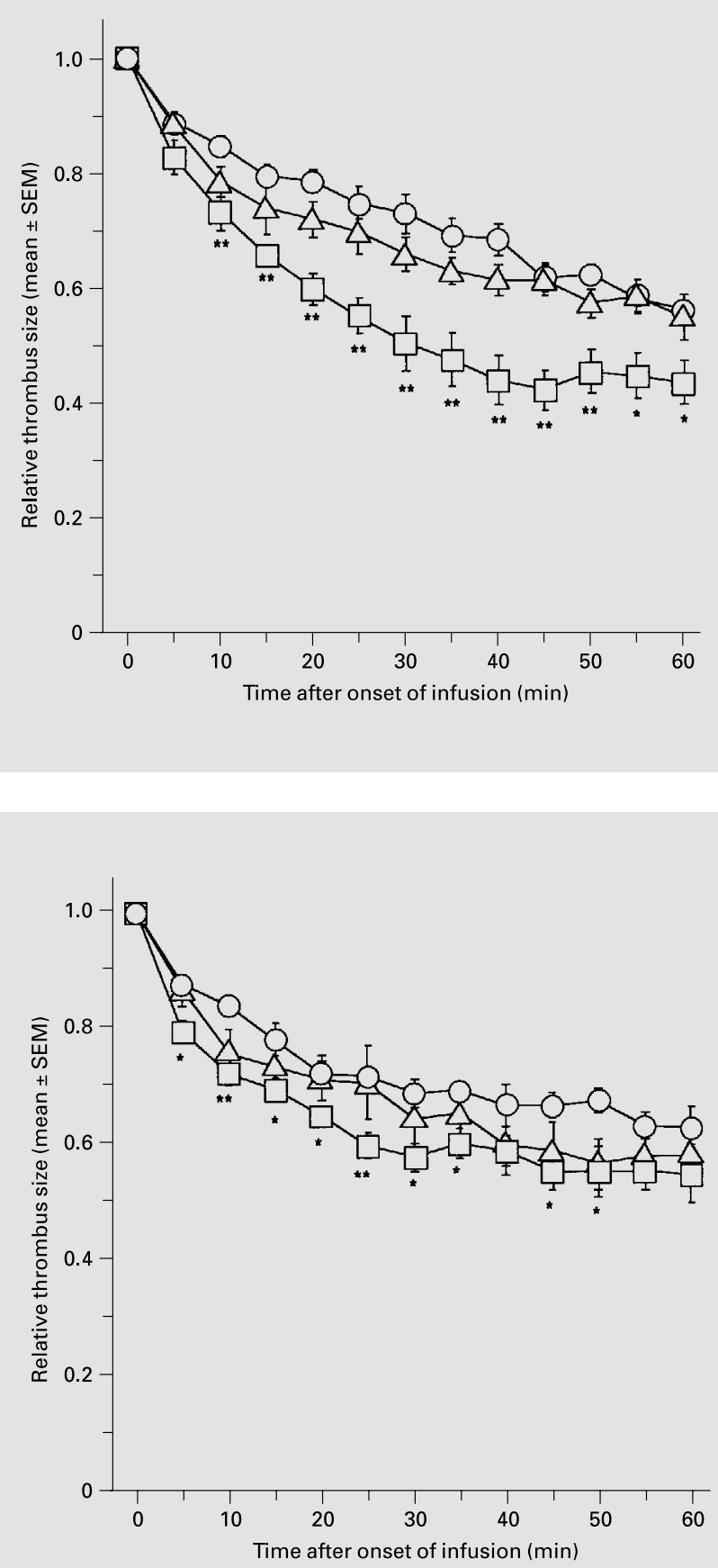
Fig. 6. Endogenous thrombolysis induced by APC alone in rat mesenteric arterioles and its inhibition by AMCA. APC at a dose of 1.62 $\mathrm{mg} / 2.0 \mathrm{ml} / \mathrm{kg}$ or vehicle was administered as a bolus injection into a femoral vein $(0 \mathrm{~min})$. AMCA at a dose of $121 \mathrm{mg} / 7.7 \mathrm{ml} / \mathrm{kg} / \mathrm{h}$ or PBS $(7.7 \mathrm{ml} / \mathrm{kg} / \mathrm{h})$ was infused through the alternative femoral vein (0-60 min). $\square=$ PBS + APC; $O=$ PBS + vehicle; $\diamond=\mathrm{AMCA}+\mathrm{APC} ; \triangle=$ AMCA + vehicle. $n=6-8$ in each group. ${ }^{a} \mathrm{p}<0.05$ versus $\mathrm{PBS}+\mathrm{ve}-$ hicle; ${ }^{b} \mathrm{p}<0.05$ versus PBS + APC at each time interval.

Fig. 7. Endogenous thrombolysis induced by argatroban alone in rat mesenteric arterioles and its inhibition by AMCA. Argatroban at a dose of $2.0 \mathrm{mg} / 4.0 \mathrm{ml} / \mathrm{kg} / \mathrm{h}$ or vehicle was infused through a femoral vein, and AMCA at a dose of 121 $\mathrm{mg} / 7.7 \mathrm{ml} / \mathrm{kg} / \mathrm{h}$ or PBS was infused through the alternative femoral vein $(0-60 \mathrm{~min} . \diamond=$ PBS + argatroban; $\mathrm{O}=\mathrm{PBS}+$ vehicle; $\square=\mathrm{AMCA}$ + argatroban; $\triangle=$ AMCA + vehicle. $\mathrm{n}=6-8$ in each group. ${ }^{\mathrm{a}} \mathrm{p}<$ $0.05 ;{ }^{b} \mathrm{p}<0.01$ versus PBS + vehicle; ${ }^{\mathrm{c}} \mathrm{p}<0.05$ versus $\mathrm{PBS}+$ argatroban at each time interval.
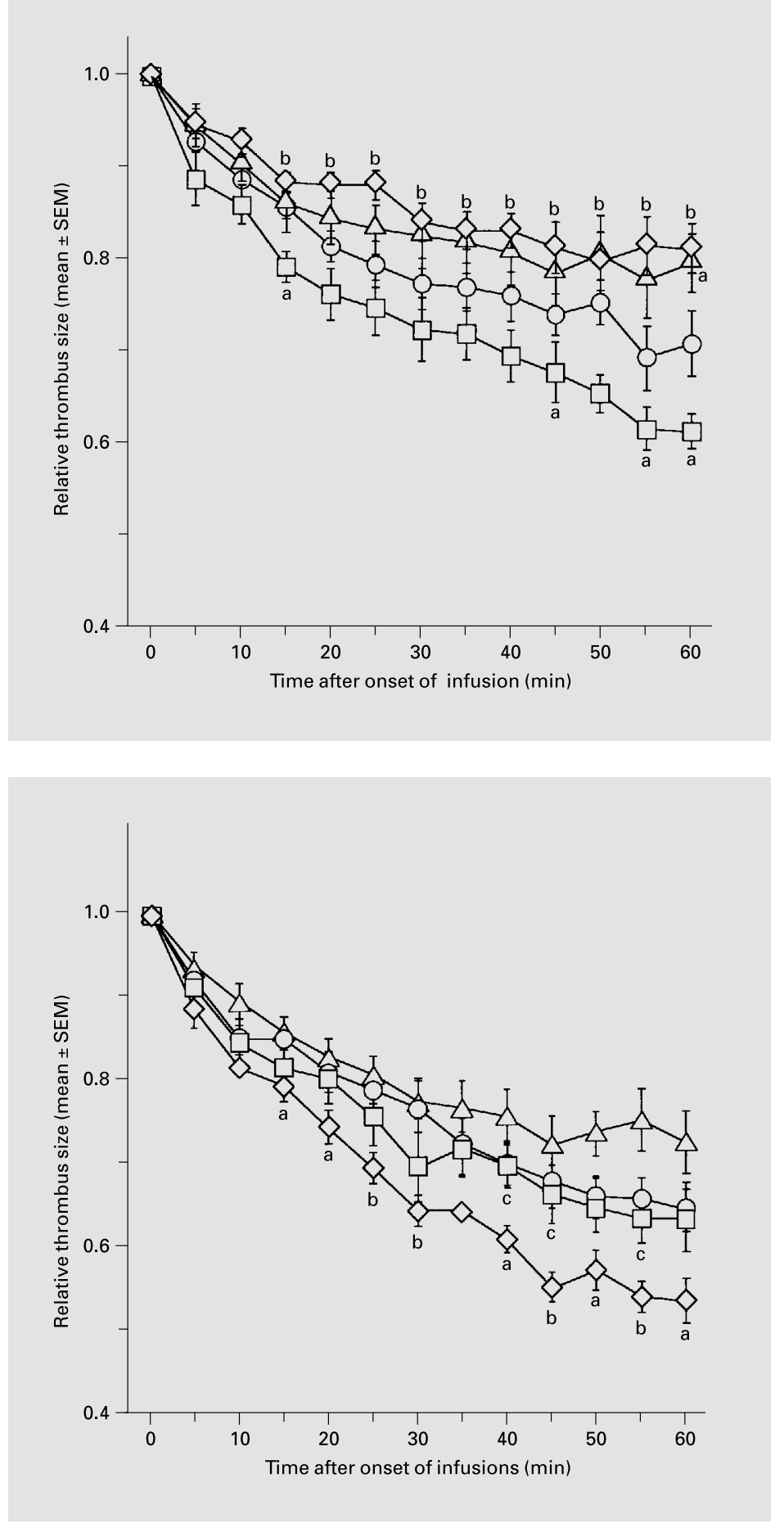
$2.31 \mathrm{ml} / \mathrm{kg}$ not only prevented the acceleration of thrombolysis induced by APC, but also inhibited thrombolysis to the level observed in the presence of AMCA alone (AMCA + vehicle).

Effect of Argatroban Alone on Spontaneous Thrombolysis. Argatroban alone at a dose of $2.0 \mathrm{mg} / 4.0 \mathrm{ml} / \mathrm{kg} / \mathrm{h}$ was infused after stabilisation of the thrombus. The results are shown in figure 7. Argatroban alone (PBS + argatroban) significantly accelerated spontaneous thrombolysis compared to the control (PBS + vehicle). AMCA prevented the accelerated thrombolysis induced by argatroban to the level observed in the control animals (PBS + vehicle), but not to the level observed in those given AMCA alone (AMCA + vehicle).

\section{Discussion}

In the presence of Evans blue, He-Ne laser irradiation induces thrombogenesis in vessels. Evans blue converts laser energy to heat resulting in disturbances of endothelial integrity and in thrombus formation. We [10] and others [11] have shown that the thrombi formed in this way are primarily platelet-rich and that platelets adhere and aggregate on morphologically uninjured endothelial cells $[10,11]$. The absence of overt endothelial damage was confirmed in the present study (fig. 2). This experimental procedure differs, therefore, from other models, which depend on endothelial denudation and fibrin-rich thrombus formation [12-17]. The minimum dose of rSAK required to significantly enhance thrombolysis in arterioles in the present study was $0.77 \mathrm{mg} / \mathrm{kg} / \mathrm{h}$. In contrast, we have previously demonstrated that the corresponding minimum dose of rSAK in venules was $5.8 \mathrm{mg} / \mathrm{kg} /$ $\mathrm{h}$ [5]. This difference in thrombolytic sensitivity might be related to the higher rate of blood flow in the arterial circulation.

Enhanced Thrombolysis by APC or Argatroban
The thrombi observed in the current investigation were densely packed with platelets and fibrin was not detected by high-magnification, transmission electron microscopy. Nevertheless, the thrombi were lysed in a dose-dependent manner by rSAK, which has a high specificity for fibrin [18-20]. Moreover, the dimensions of the He-Ne laserinduced thrombi were decreased by $29-36 \%$ in $60 \mathrm{~min}$ in the absence of any exogenous fibrinolytic agents, and these decreases were partially suppressed by AMCA (fig. 6, 7). Some spontaneous decrease in thrombus size was apparent, even in the presence of AMCA; the role that other cellular products, such as leukocyte elastase, play in these thrombinrelated reactions remains to be evaluated. Moreover, AMCA not only inhibited spontaneous or endogenous thrombolysis but also prevented the APC- or argatroban-induced enhancement of thrombolysis. In the presence of argatroban, however, the level of inhibition did not reach that observed with AMCA alone. The reasons for these discrepancies remain to be fully explored, but it may be that the continuous inactivation of thrombin by argatroban contributed to the thrombolytic mechanisms. AMCA is not an active sitedirected inhibitor of plasmin but specifically inhibits the binding of plasminogen or plasmin to fibrin resulting in depressed fibrinolysis [21]. It seems likely, therefore, that although we failed to detect fibrin morphologically in our He-Ne laser-induced thrombi, fibrin-related reactions were involved in the thrombogenic mechanisms.

The rSAK-induced thrombolysis observed in the present in vivo experiments was further enhanced by the inhibition of thrombin and its generation by argatroban and APC, respectively. These results were consistent with other in vitro investigations which demonstrated that PA-induced thrombolysis was accelerated by APC [22]. APC is known to inhibit the

Haemostasis 2001;31:80-89 
coagulation cascade, resulting in decreased thrombin generation. Thus, fibrin formation and platelet aggregation may be suppressed leading to more rapid thrombus dissolution. This seems to be true also for argatroban. Our original hypothesis was that the enhancement of rSAK-induced thrombolysis by argatroban and APC may be due to the inhibition of thrombus growth. The present study demonstrated, however, that spontaneous thrombolysis occurred in the absence of any agents, and that APC and argatroban enhanced these endogenous mechanisms. The precise modes of action of APC and argatroban remain to be clarified, but the present findings were in keeping with the suggestion that APC and argatroban moderate endogenous thrombolysis or fibrinolysis by attenuating the activity of thrombin-activatable fibrinolysis inhibitor [23-27]. Furthermore, it has been shown that rSAK per se can increase endogenous APC [28], and it may be that the inactivation of thrombin-activatable fibrinolysis inhibitor contributes to the enhancement of rSAKinduced thrombolysis mediated by APC and argatroban.

In conclusion, we have established a simple and reproducible model of arterial thrombolysis using rat mesenteric microvessels. The present findings demonstrated that enhanced thrombolysis induced by argatroban or APC in the presence or absence of rSAK is mediated by accelerated endogenous thrombolytic activities. The present model offers a useful protocol for assessing the relationship between thrombin-activatable fibrinolysis inhibitor, APC, argatroban, and thrombolysis in vivo.

\section{Acknowledgements}

We thank Dr. T. Yamashita, Dr. Y. Sasaki and Ms. T. Taka, Laboratory of Physiology, Faculty of Nutrition, Kobe Gakuin University, for their advice and discussion on this work.

\section{References}

1 Owen J, Friedman KD, Grossman BA, Wilkins C, Berke AD, Powers ER: Thrombolytic therapy with tissue plasminogen activator or streptokinase induces transient thrombin activity. Blood 1988;72:616-620.

2 Rapold HJ, Kuemmerli H, Weiss M, Baur H, Haeberli A: Monitoring of fibrin generation during thrombolytic therapy of acute myocardial infarction with recombinant tissuetype plasminogen activator. Circulation 1989;79:980-989.

3 Antman EM, for the TIMI 9A Investicators: Hirudin in acute myocardial infarction: Safety report from the thrombolysis and thrombin inhibition in myocardial infarction (TIMI) 9A trial. Circulation 1994; 90:1624-1630.
4 GUSTO IIb investigators: A comparison of recombinant hirudin with heparin for the treatment of acute coronary syndromes. N Engl J Med 1996;335:775-782.

5 Kawano M, Watanabe S, Sasaki Y, Giddings JC, Yamamoto J: Adjuvant effect of argatroban on staphylokinase induced thrombolysis of platelet rich thrombi in rat mesenteric venules in vivo. Thromb Res 1997;86:115-126.

6 Yamamoto J, Kawano M, Hashimoto M, Sasaki Y, Yamashita T, Taka T, Watanabe S, Giddings JC: Adjuvant effect of antibodies against von Willebrand factor, fibrinogen, and fibronectin on staphylokinase-induced thrombolysis as measured using mural thrombi formed in rat mesenteric venules. Thromb Res 2000;97:327-333.
7 Nagamatsu Y, Tsujioka Y, Hashimoto M, Giddings JC, Yamamoto J: The differential effects of aspirin on platelets, leukocytes and vascular endothelium in an in vivo model of thrombus formation. Clin Lab Haematol 1999;21:33-40.

8 Kovacs IB, Tigyi-Sebes A, Trombitas K, Gorog P: Evans blue: An ideal energy-absorbing material to produce intravascular microinjury by $\mathrm{He}-\mathrm{Ne}$ gas laser. Microvasc Res 1975;10:107-124.

9 Yamamoto J, Iizumi H, Hirota R, Shimonaka K, Nagamatsu Y, Horie N, Morita S: Effect of physical training on thrombotic tendency in rats: Decrease in thrombotic tendency measured by the $\mathrm{He}-\mathrm{Ne}$ laser-induced thrombus formation method. Haemostasis 1989;19:260-265. 
10 Yamamoto J, Oyama T, Ishii I, Okita N, Sasaki Y, Yamashita T, Matsuoka A, Muraki T, Giddings JC, Watanabe S, Seki J: The differential involvement of von Willebrand factor, fibrinogen and fibronectin in acute experimental thrombosis in rat cerebral and mesenteric microvessels. Jpn J Physiol 1997;47:431441.

11 Povlishock JT, Rosenblum WI: Injury of brain microvessels with a helium-neon laser and Evans blue can elicit local platelet aggregation without endothelial denudation. Arch Pathol Lab Med 1987;111:415421.

12 Schneider J: Heparin and the thrombin inhibitor argatroban enhance fibrinolysis by infused or bolus-injected saruplase (r-scu-PA) in rabbit femoral artery thrombosis. Thromb Res 1991;64:677-689.

13 Gold HK, Yasuda T, Jang I, Guerrero JL, Fallon JT, Leinbach RC, Collen D: Animal models for arterial thrombolysis and prevention of reocclusion. Circulation 1991;83 (suppl 6):IV26-IV40.

14 Klement P, Borm A, Hirsh J, Maraganore $\mathrm{J}$, Wilson $\mathrm{G}$, Weitz $\mathrm{J}$ : The effect of thrombin inhibitors on tissue plasminogen activator induced thrombolysis in a rat model. Thromb Haemost 1992;68:64-68.

15 Meyer BJ, Badimon JJ, Chesebro JH, Fallon JT, Fuster V, Badimon L: Dissolution of mural thrombus by specific thrombin inhibition with $\mathrm{r}$ hirudin. Circulation 1998;97:681685 .
16 Stassen JM, Lijnen HR, Kieckens L, Collen D: Small animal thrombosis models for the evaluation of thrombolytic agents. Circulation 1991; 83(suppl 6):IV65-IV72.

17 Umemura K, Wada K, Uematsu T, Nakashima M: Evaluation of the combination of a tissue-type plasminogen activator, SUN9216, and a thromboxane A2 receptor antagonist, vapiprost, in a rat middle cerebral artery thrombosis model. Stroke 1993;24:1077-1082.

18 Sakai M, Watanuki M, Matsuo O: Mechanism of fibrin-specific fibrinolysis by staphylokinase: Participation of $\alpha 2$-plasmin inhibitor. Biochem Biophys Res Commun 1989; 163:830-837.

19 Matsuo O, Okada K, Fukao H, Tomioka Y, Ueshima S, Watanuki M, Sakai M: Thrombolytic properties of staphylokinase. Blood 1990; 76:925-929.

20 Lijnen HR, Hoef BV, Cock FD, Okada K, Ueshima S, Matsuo O, Collen D: On the mechanism of fibrin-specific plasminogen activation by staphylokinase. J Biol Chem 1991;266:11826-11832.

21 Iwamoto M: Plasminogen-plasmin system IX. Specific binding of tranexamic acid to plasmin. Thrombus Diathes Haemorrh 1975;33:573585 .
22 Bajzar L, Nesheim ME, Tracy PB: The profibrinolytic effect of activated protein $\mathrm{C}$ in clots formed from plasma is TAFI-dependent. Blood 1996;88:2093-2100.

23 Griffin JH: The thrombin paradox. Nature 1997;378:337-338.

24 Wang W, Boffa MB, Bajzar L, Walker JB, Nesheim ME: A study of the mechanism of inhibition of fibrinolysis by activated thrombin-activable fibrinolysis inhibitor. $\mathrm{J}$ Biol Chem 1998;273:27176-27181.

25 Bajzar L, Nesheim M, Morser J, Tracy PB: Both cellular and soluble forms of thrombomodulin inhibit fibrinolysis by potentiating the activation of thrombin-activable fibrinolysis inhibitor. J Biol Chem 1998;273: 2792-2798.

26 Bajzar L, Nesheim M: The effect of activated protein $\mathrm{C}$ on fibrinolysis in cell-free plasma can be attributed specifically to attenuation of prothrombin activation. J Biol Chem 1993;268:8608-8616.

27 Von dem Borne PA, Bajzar L, Meijers JC, Nesheim ME, Bouma BN: Thrombin-mediated activation of factor XI results in a thrombin-activatable fibrinolysis inhibitor-dependent inhibition of fibrinolysis. J Clin Invest 1997;99:2323-2327.

28 Gruber A, Pal A, Kiss RG, Sas G, Griffin JH: Generation of activated protein $\mathrm{C}$ during thrombolysis. Lancet 1993;342:1275-1276. 